2016-07-01

Farm characteristics and farmer perceptions associated with bovine tuberculosis incidents in areas of emerging endemic spread

Broughan, JM

http://hdl.handle.net/10026.1/14645

10.1016/j.prevetmed.2016.05.007

Preventive Veterinary Medicine

Elsevier

All content in PEARL is protected by copyright law. Author manuscripts are made available in accordance with publisher policies. Please cite only the published version using the details provided on the item record or document. In the absence of an open licence (e.g. Creative Commons), permissions for further reuse of content should be sought from the publisher or author. 


\title{
Farm characteristics and farmer perceptions associated with bovine tuberculosis incidents in areas of emerging endemic spread
}

\author{
J.M. Broughan a,*, D. Maye ${ }^{\mathrm{c}}$, P. Carmody ${ }^{\mathrm{f}}$, L.A. Brunton ${ }^{\mathrm{a}}$, A. Ashton ${ }^{\mathrm{a}}$, W. Wint ${ }^{\mathrm{g}}$, \\ N. Alexander ${ }^{\mathrm{g}}$, R. Naylor ${ }^{\mathrm{d}}$, K. Ward ${ }^{\mathrm{b}}$, A.V. Goodchild ${ }^{\mathrm{a}}$, S. Hinchliffe ${ }^{\mathrm{e}}$, R.D. Eglin ${ }^{\mathrm{a}}$, \\ P. Upton ${ }^{\mathrm{a}}$, R. Nicholson ${ }^{\mathrm{a}}$, G. Enticott ${ }^{\mathrm{b}}$
}

a Animal and Plant Health Agency, Weybridge, Woodham Road, New Haw, Surrey KT15 3NB, UK

${ }^{\mathrm{b}}$ School of Planning and Geography, Cardiff University, King Edward VII Avenue, Cardiff CF10 3WA, UK

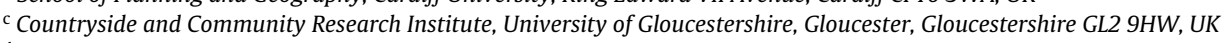

${ }^{\mathrm{d}}$ Royal Agricultural University, Stroud Road, Cirencester, Gloucestershire GL7 6JS, UK

e Department of Geography, Exeter University, Rennes Drive Exeter EX4 4RJ, UK

${ }^{\mathrm{f}}$ Agile Information, London, UK

${ }^{g}$ Environmental Research Group Oxford, Oxford University, South Parks Road, Oxford OX1 3PS, UK

\section{A R T I C L E I N F O}

\section{Article history:}

Received 5 January 2016

Received in revised form 10 May 2016

Accepted 13 May 2016

\section{Keywords:}

Bovine tuberculosis

Risk factor

Questionnaire

Case-control study

\begin{abstract}
A B S T R A C T
While much is known about the risk factors for bovine tuberculosis (bTB) in herds located in high incidence areas, the drivers of bTB spread in areas of emerging endemicity are less well established. Epidemiological analysis and intensive social research identified natural and social risk factors that may prevent or encourage the spread of disease. These were investigated using a case-control study design to survey farmers in areas defined as recently having become endemic for bTB (from or after 2006). Telephone surveys were conducted for 113 farms with a recent history of a bTB incident where their officially tuberculosis free status had been withdrawn (OTFW) (cases) and 224 controls with no history of a bTB incident, matched on location, production type and the rate of endemic bTB spread. Farmers were questioned about a range of farm management strategies, farm characteristics, herd health, wildlife and biosecurity measures with a focus on farmer attitudes and behaviours such as farmers' perception of endemicity and feelings of control, openness and social cohesion. Data generated in the telephone surveys was supplemented with existing herd-level data and analysed using conditional logistic regression. Overall, herd size (OR 1.07), purchasing an animal at a cattle market compared to purchasing outside of markets (OR 2.6), the number of contiguous bTB incidents (2.30) and the number of inconclusive reactors detected in the 2 years prior to the case incident (OR 1.95) significantly increased the odds of a bTB incident. Beef herds using a field parcel more than $3.2 \mathrm{~km}$ away from the main farm and dairy herds reporting Johne's disease in the previous 12 months were 3.0 and 4.7 times more likely to have a recent history of a bTB incident, respectively. Beef herds reporting maize growing near, but not on, their farm were less likely to be case herds. Operating a closed farm in the two years prior to the case breakdown did not reduce the odds of a bTB incident. Farmers that had recently experienced a bTB incident were more likely to have implemented badger biosecurity in the previous year, but no more likely than control farms to have implemented cattle biosecurity. Case farmers felt significantly less likely to be influenced by government, vets or other farmers compared to those with no history of bTB. This suggests that alternative methods of engaging with farmers who have recently had a breakdown may need to be developed.
\end{abstract}

Crown Copyright @ 2016 Published by Elsevier B.V. All rights reserved.

\section{Introduction}

Despite increasing efforts and controls to slow the spread of bovine tuberculosis (bTB), the area affected by endemic bTB in Eng-

\footnotetext{
* Corresponding author.

E-mail address: jennifer.broughan@apha.gsi.gov.uk (J.M. Broughan).
}

land and Wales continues to expand (Broughan et al., 2015) though the increasing trend in the incidence of bTB in England (Abernethy et al., 2013) is not uniform. The lack of uniformity has been recognised by Defra who have divided England into three distinct spatial units, each associated with different disease management strategies, in an attempt to stem the east- and northward spread of bTB. These areas are the High Risk Area (HRA) where incidence has been historically high, the Low Risk Area (LRA) that represents the major- 
ity of herds in the north and east of the country and the space in between called the Edge Area (Defra, 2014).

There is considerable interest in the drivers of the spread of bTB north- and eastward from the traditional endemic core areas of south west Wales \& England and western England. While herdlevel risk factors have been relatively well studied for herds in the high incidence areas of England and Wales (Johnston et al., 2005; Reilly and Courtenay, 2007; Carrique-Mas et al., 2008; RamírezVillaescusa et al., 2010; Johnston et al., 2011; Karolemeas et al., 2011; Vial et al., 2011; Mill et al., 2012), Northern Ireland (Denny and Wilesmith, 1999), Ireland (Griffin et al., 1993; Griffin et al., 1996), Europe (Marangon et al., 1998; Garro et al., 2010; Humblet et al., 2010) and further afield (Kaneene et al., 2002; Porphyre et al., 2008; Javed et al., 2011), the factors that predispose or protect a herd against bTB are less well defined in areas of emerging endemicity. There are often inconsistencies in the risk factors that different studies identify, and most are based in long-standing endemic areas. Different risk factors may operate regionally in accordance with varying bTB incidence (Johnston et al., 2011)

This research forms part of a larger multidisciplinary approach combining GIS, epidemiological and social research expertise to characterise the spread of endemic bTB and to identify relevant farm practices, attitudes and behaviours that may prevent or encourage the spread of disease. Previous work has defined and measured endemic spread (Brunton et al., 2015). To identify herd level risk factors that may be operating in areas recently endemic for bTB, we deployed a telephone questionnaire exploring a range of farm management, general farm characteristics, herd health, wildlife and cattle biosecurity measures.

Previous work has recognised that the ability to come up with solutions for complex problems can benefit from integrating between several analytical approaches and knowledge generated by different scientific disciplines (Kristensen and Jakobsen, 2011; Wentholt et al., 2012). Studies from participatory epidemiology have highlighted the importance of capturing and including farmers' understandings of disease in scientific analyses of disease transmission (Catley et al., 2012; Leach and Scoones, 2013). This is particularly relevant for diseases such as bTB where trust in science and/or the institutions that produce scientific knowledge has proved to be an important limitation to bTB policy (Enticott, 2008). Our approach to defining potential risk factors has therefore included exploring traditional risk factors such as farm characteristics and management, but also included exploring factors relating to farmers' perceptions, attitudes and behaviours in relation to bTB.

This paper aims to investigate the differences between farms in recently endemic areas with a recent history of bTB with those in similar areas that have no experience of bTB and identify risk factors operating under this level of infection. It also aims to explore how farmers' behaviour, attitudes and farming practices are likely to be informed by different disease experience.

\section{Materials and methods}

\subsection{Study population}

The sampling frame was derived from maps of the spread of endemic bTB. In other work associated with this study a mathematical definition of endemicity was developed from which the expansion of the area affected by endemic bTB through time using data from bTB testing was mapped. Hexagonal cells with an area of $6.25 \mathrm{~km}^{2}$ were overlaid on a map of England and Wales and gained endemic status based on the proximity and recurrence of bTB incidents on a two yearly basis between 2002 and 2012 (Brunton et al., 2015). Analysis focussed only on herds classified as Officially Tuberculosis Free Status Withdrawn (OTFW), which at that time period in GB was defined as a bTB incident which was confirmed at post mortem by the presence of visible lesions or bacterial confirmation of Mycobacterium bovis. Briefly, a cell was defined as endemic for bTB if there were three OTF-W incidents within $7 \mathrm{~km}$ of a farm within that hexagon over the time period assessed. Maps of the endemic areas were produced for nine overlapping 24 month intervals between 1st September 2001 and 31st August 2011, and the temporal spread rate of endemic bTB was estimated by overlaying the endemic areas from each time period and creating a contourlike map displaying the spread of endemic bTB over the two-year periods, from which a rate of spread was calculated. The target population was defined as all herds within hexagons defined as newly endemic. To achieve the appropriate number of cases for a statistically adequate sample size, newly endemic was defined as a hexagon through which the endemic front passed since 2006. A case was defined as herd that was located in a newly endemic hexagon, in which at least one reactor to the Single Intradermal Comparative Cervical Tuberculin (SICCT) at standard interpretation was identified and post mortem confirmation of infection was obtained, between 1st January 2011 and the 17th January 2014. Controls were defined as herds that had no record of a bTB incident in the database. As production types are managed differently and location is known risk factor for a bTB incident (White et al., 2013), cases were matched to controls within the same hexagon if possible or within a maximum of $25 \mathrm{~km}$ from each other (in one case this was extended to $70 \mathrm{~km}$ ) and matched to the same main production type (beef/dairy).

\subsection{Sample size and selection}

Allowing for two controls for every case, 224 controls and 112 cases were required to detect a 2 fold increase in the odds at $80 \%$ statistical power and $5 \%$ statistical significance level for a risk factor that is present on $25 \%$ of control farms (WinEpiscope 2.0 ).

Cases were matched to up to five selected controls to improve the probability of attaining a 1:2 ratio of cases to controls. Randomisation was conducted using an MS Access VBA script interrogating the APHA SAM database. Once one control was found for a case it moved on to the next case, so as to allocate controls to cases evenly. A herd could not be a control for more than one case. Controls were ranked according to the distance from the case, with nearer herds being given lower ranks. Interviewers were encouraged to contact the control farm with the lowest rank, until they had two controls. A flow diagram describing the inclusion of farms to the study is presented in Fig. 1.

\subsection{Questionnaire design}

The survey design and implementation has been described in detail by (Enticott et al., 2015). The survey was thus designed to build on and extend work completed in previous epidemiological and social science research phases, combining social risk factors with farm practice and physical factors. To summarise, information on farmer attitudes, behaviours, practices and environmental conditions that may influence their disease status was generated based on a large-scale review of the existing scientific literature and was further refined during nine focus groups held with vets and farmers in different locations within the Edge Area (including, Cheshire, Leicestershire and Nottinghamshire). Focus group participants rated the significance of risk factors identified in a previous spatial analysis that affect the rate of spread, as well as other factors based on their own opinion. Other questions related to risk factors for farm-level endemic spread were identified by assessing the recent literature and prioritised using expert opinion. The survey included items on social factors such as farmer's perceived control of bTB and knowledge of bTB in their local area, as well as farm- 


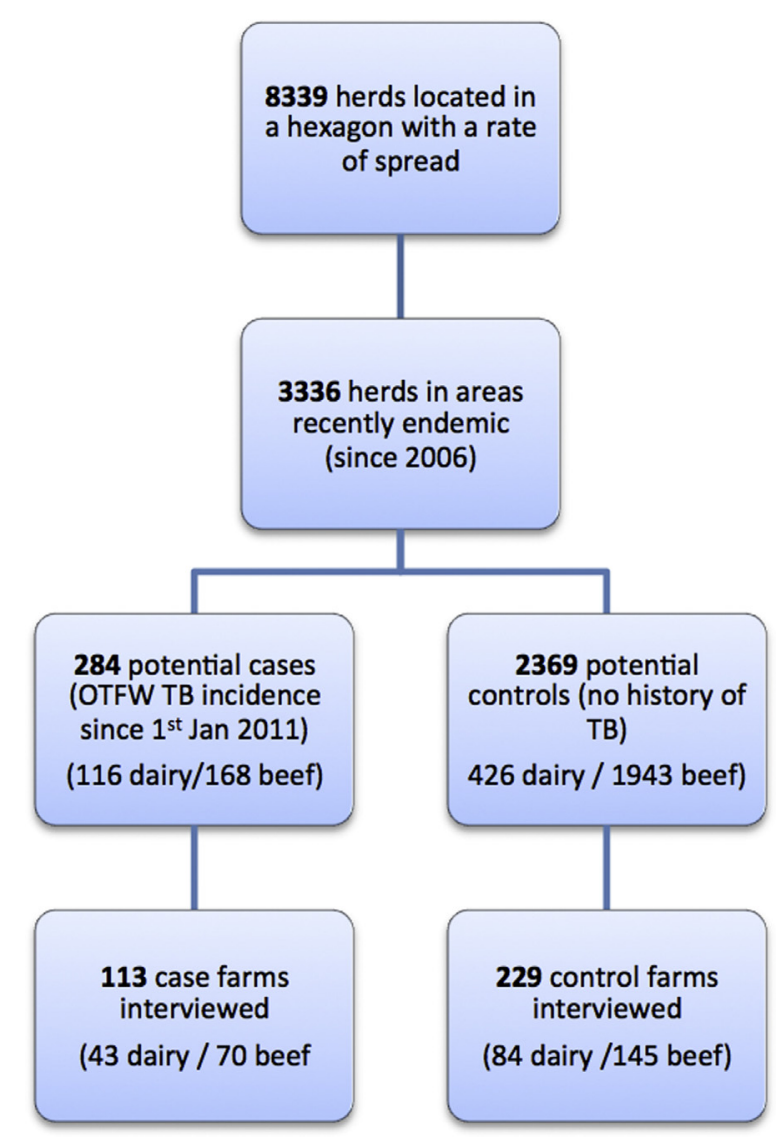

Fig. 1. A flow diagram describing the study population and inclusion of farms.

ing practices such as biosecurity measures and farm management practices in place.

Risk factors identified by these methods, for which data were not already available, were included in the survey (Table 1). These included: farm management information; cattle and badger biosecurity activities; farm fragmentation; concurrent disease and herd health; within-farm cattle movements; farm boundaries; flooding history; and presence of maize. Behavioural risk factors were informed by the focus groups but also reflected theoretical models of farmer behaviour. The survey explored farmers' own perceptions of bTB risks and threats; their own perceived ability and the ability of others to control disease and the influence of others to reduce bTB (such as other farmers and vets); their connectedness with others (e.g. farmers and vets) who could help and advise at times of crisis; and their openness to new ideas and initiatives to control bTB (specifically the disclosure of bTB status to all farmers). The questionnaire is available on request.

The questionnaire was initially piloted with 5 farmers, after which the wording for some survey items was refined. The survey was conducted between April and May 2014 by eight interviewers who all attended a training day to ensure that each adopted the same approach during the survey. The survey was delivered via telephone and took approximately $20 \mathrm{~min}$.

\subsection{Additional data sources}

Questionnaire data was supplemented by additional herd level data extracted from the Animal and Plant Health Agency (APHA)'s database SAM release 6 and Cattle Tracing System (CTS) (British Cattle Movement Service). Additional variables extracted at a herd level from existing data are presented in Table 2. Data were extracted for the two years prior to the incident in the case farm for each case-control set.

\subsection{Data management}

Survey responses were entered directly into an Access database during the telephone survey and imported into Stata IC v12 (Statacorp, College Station, TX) for further analysis. Survey responses from each farm were linked to data from existing databases using the unique identifier $\mathrm{CPH}$ (Table 2). Data were summarized according to characteristics of farmers to explore how farmers' bTB status is linked to environmental and social risk factors.

\subsection{Data analysis}

Summary descriptive statistics for all continuous and categorical variables were calculated separately for cases and controls. Herd size was that reported by the farmer. Stocking density was estimated from the area of the farm and the herd size reported by the farmer. Herd type was the designation on SAM.

Conditional logistic regression analyses were conducted on the cases and their matched control(s). These results were presented in two sets of models. Analysis was conducted on the whole dataset in the first instance, and was then stratified according to herd type (beef/dairy). Farm characteristic models were constructed, and then these models were used as the base models to which the data on farmer perceptions and behaviours were added.

Univariate conditional logistic regression was used to calculate odds ratios (ORs), the corresponding 95\% confidence intervals (CI) and the Wald test P-values for the risk factors.

Principal components analysis (PCA) was conducted in SPSS v22 and used to combine variables relating to farmer perceptions of bTB. The PCA with varimax rotation extracted seven components from 21 variables accounting for 59.08\% of data variance. KaiserMeyer-Olkin measure of sampling adequacy was an acceptable 0.730. Interpretation of the components revealed the following themes: variables in component 1 related to farmers' perceptions of their disease risk (accounting for $13.37 \%$ of variance); component 2 related to farmers' openness to new bTB policy (explaining 9.93\% of variance); component 3 related to farmers' locus of control (9.71\% of variance); component 4 related to farmers' sources of information on bTB (8.51\% of variance); component 5 related to farmers' community support (6.29\% of variance); component 6 related to farmers' perceived self-efficacy (5.65\% of variance); and component 7 referred to farmers' use of IT in relation to bTB management (5.62\% of variance). The SPSS "Extract" command was used to extract variables describing these seven components for the regression analysis. Detailed descriptions of farmer perceptions and attitudes towards bTB are presented elsewhere (Enticott et al., 2015).

The conditional logistic regression analysis was performed using the clogit function in Stata v12. The model was constructed using a backward stepwise deletion process including all variables that had a statistical significance $P>0.2$ in the univariate analysis (Hosmer et al., 2013). The variable of least significance, as measured by the lowest Wald statistic in each model run, was removed. Models were compared by examining the change in the Akaike's information criterion (AIC) and the model with the lowest AIC was retained. Collinearity between predictor variables was explored prior to modelling by testing for pair-wise correlations between the explanatory variables and, following the model fitting, by stepwise removal of variables to assess the effect on the covariate estimates and their standard errors. Correlation matrices of the covariate estimates were also checked for collinearity. Variables from the same risk factor group (e.g. herd size, farm size) that were likely to be collinear, were added individually and the variable that had the 
Table 1

Description of the main risk factors investigated in the questionnaire.

\begin{tabular}{|c|c|}
\hline Risk factor group & Description \\
\hline Farmer characteristics & Age, gender \\
\hline Farm characteristics & Herd size, type, pedigree, farm size, proportion of income generated by cattle, \\
\hline Farm management & Cattle housing, within farm cattle movements, fragmentation, farm boundaries, maize \\
\hline Herd health & Liverfluke, Johnes, BVD, membership of a herd health scheme. \\
\hline Flooding & Flooding prior to Dec 2013, feed/grazing affected \\
\hline Badger activity & Aware of badger activity on their land \\
\hline Badger Biosecurity & $\begin{array}{l}\text { Prevent badgers accessing housing/feed stores/silage clamps. Raising cattle feed \& water troughs. } \\
\text { Fencing off badger setts }\end{array}$ \\
\hline Cattle Biosecurity & $\begin{array}{l}\text { Avoid buying cattle from high risk areas, questioning the disease history of potential purchases, } \\
\text { isolating purchased cattle. Adapting grazing to avoid high risk fields }\end{array}$ \\
\hline $\begin{array}{l}\text { Perceived level of } \\
\text { disease }\end{array}$ & How fast is bTB spreading, the threat that is represented by badgers and cattle \\
\hline Control over bTB & $\begin{array}{l}\text { The role of luck and control in sustaining a breakdown. Following advice from private vets, other } \\
\text { farmers or the government }\end{array}$ \\
\hline $\begin{array}{l}\text { Connectedness \& } \\
\text { isolation }\end{array}$ & Where they go for advice and information. Neighbour interaction. \\
\hline Openness & Other farmers perceptions, how public bTB incident information should be made \\
\hline
\end{tabular}

strongest relationship with the dependent variable and produced the model with the lowest AIC was retained. Continuous variables were log-transformed if by doing so reduced the AIC. Where appropriate, categorical variables were compiled using quartiles of the data. Epidemiologically-plausible two-way interactions were tested. Non-significant variables that substantially reduced the AIC were retained. Categorical variables were only included if the number of observations in each category was five or more. Residuals were calculated to examine the influence of outliers. Lack of fit, delta beta influence and leverage statistics were examined; outliers were removed and the model was rerun to assess the impact of this change (Hosmer et al., 2013).

\section{Results}

A total of 8339 herds were located in areas that had a rate of endemic spread calculated in two year windows between 2001 and 2012. Of these, 3336 herds were located in cells that were defined as recently endemic. An OTF-W incident within the previous three years was recorded in 284 herds and 2369 herds had no history of an incident and so were potential controls (Figs. 1,2).

Telephone interviews were conducted for 346 farms in total; 117 cases and 229 controls, a 70\% response rate. Of these, four cases and four controls were dropped from the regression analyses as corresponding cases or controls were not available. One control had a bTB incident after the data were extracted and so was discarded and the corresponding case was not available for six controls, leaving 113 farms with a recent history of an OTF-W incident and 218 matched controls in the conditional logistic regression. Each case had between 1 and 3 controls, although 86.7\% had two controls.

Dairy herds represented $41 \%$ of all the potential cases (116/284), while they represent $18 \%$ of the total study population. Therefore a target of 50 cases in dairy herds was set, to facilitate meaningful comparisons by herd type given this over-representation of dairy herds in the case population relative to the proportion of potential study herds. Forty-three dairy cases and 84 controls were interviewed, a sample size that was sufficient to detect a minimum OR of 2.9 at $80 \%$ power and $95 \%$ confidence.

\subsection{Farm characteristics: univariate analysis}

The descriptive statistics for the main farm characteristics are shown in Fig. 3. Other descriptive statistics for farm characteristics and by herd type are listed in Supplementary material Tables S1-S4.

Case and control farms differed with regard to farm characteristics and farm management practices (Fig. 3; Supplementary material tables S1 \& S2). Case farms were bigger in area, had more animals, operated over a higher number of premises and depended on cattle for a higher proportion of their income (all $\mathrm{p}<0.001$; supplementary material Table S1). Case farms were more fragmented than control farms with more parcels of land which were more dispersed ( $p<0.001$; Fig. 3 ) and were more likely to have had 2 or more

Table 2

Additional existing herd-level data extracted: data for the 2 years prior to the incident in the case herd.

\begin{tabular}{|c|c|}
\hline Variable & Source \\
\hline $\begin{array}{l}\text { Mean \& median age of cattle on holding at the time of the incident for the case herd. } \\
\text { Total number of cattle } \\
\text { Purchasinga } \\
\text { - Number/proportion of on movements } \\
\text { - Number of markets where cattle are sourced. Number/Proportion of animals moved on through market } \\
\text { - } 25 \text { th, } 50 \text { th \& } 75 \text { th centile distance }(\mathrm{km}) \text { of movements onto the farm } \\
\text { - Number/proportion of cattle moved on from endemic pre } 2001 \text { area } \\
\text { - Number/proportion of movements from a herd with a history of any/OTFW bTB incident }{ }^{\mathrm{b}}\end{array}$ & $\begin{array}{l}\text { CTS } \\
\text { CTS } \\
\text { CTS CTS/SAM }\end{array}$ \\
\hline $\begin{array}{l}\text { Number/proportion of movements to slaughter }{ }^{\mathrm{a}} \\
\text { Number of herd level skin tests (unrestricted) } \\
\text { Number of Inconclusive reactors to the Single Intradermal Comparative Cervical Tuberculin (SICCT) test (unrestricted) } \\
\text { Parish Testing Interval at time of case incident } \\
\text { Number of contiguous premises with any/OTFW incident }{ }^{\mathrm{c}}\end{array}$ & $\begin{array}{l}\text { CTS } \\
\text { SAM } \\
\text { SAM } \\
\text { SAM } \\
\text { SAM }\end{array}$ \\
\hline
\end{tabular}

a For the 2 years prior to the incident in the case herd.

b bTB history - look back 3 years and forward 1 year. Movements within 2 years of case incident.

c Incident on the contiguous premises within 3 years of the case incident. 


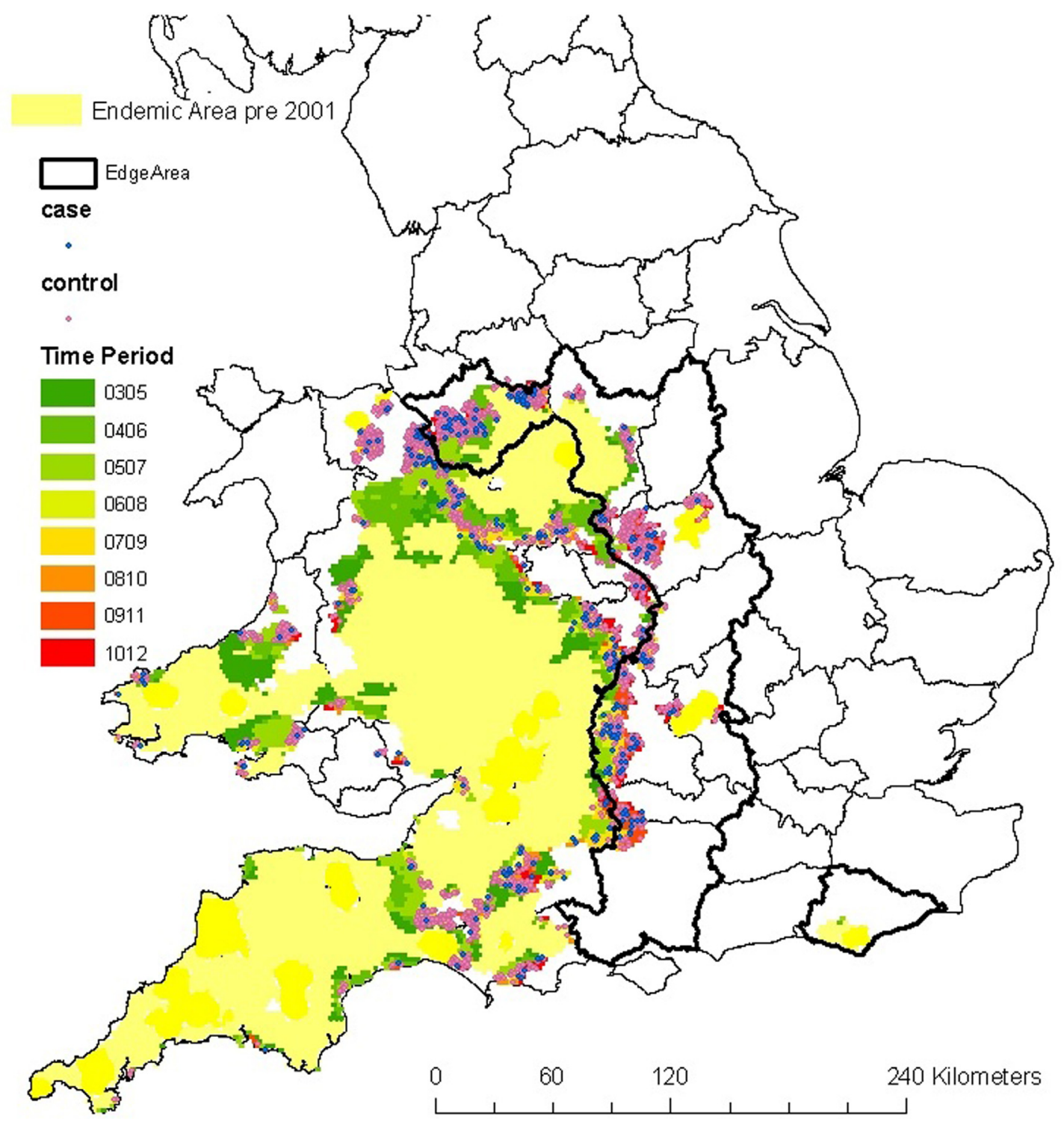

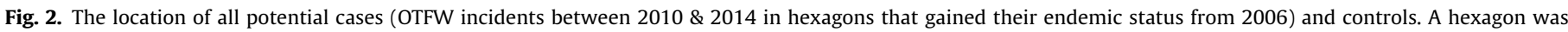

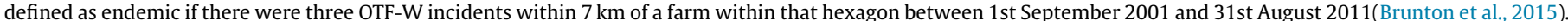
The scale shows the time period a hexagon became endemic.

contiguous bTB incidents $(\mathrm{P}<0.05)$. More control farms were closed herds (i.e. there was no recorded on-movement in the 2 years prior to the case incident $)(P=0.023$, Fig. 3$)$. Farms that grew maize were twice as likely to be cases ( $\mathrm{p}=0.04$; Fig. 3 ) and farms that reported an occurrence of Johne's disease within the past year were three times more likely to be case farms $(p=0.001$; Fig. 3$)$. The proportion of case farms that had reported Johne's disease in the previous year was associated with herd size and beyond 150 animals there was no difference between cases and controls $(p=0.2)$.

In dairy herds, the differences between measures of farm sizes were less pronounced, although dairy case herds were significantly larger than dairy control herds (Supplementary material Table 1). The effect of fragmentation was less pronounced for dairy herds, as $44.2 \%$ of case herds were fragmented compared with $40.9 \%$ of controls (supplementary material Table 3 ), which was a significant but small difference. Johne's disease was more common in case farms (48.8\%) compared with control farms (15.7\%).

Similar univariate relationships were found between case and controls in beef herds (Supplementary material Tables 1 \& 4). All measures of fragmentation were more common in cases than controls (Supplementary material Table 4 ). $17.4 \%$ of case beef farms reported liverfluke in the herds in the previous year compared to $4 \%$ of the controls (OR $4.95, \mathrm{P}=0.007$ ) but there were no other differences in farm characteristics between cases and controls.

\subsection{Farm characteristics: multivariate analysis}

Herd size, the presence of inconclusive reactors to the SICCT and the number of breakdowns in contiguous herds in the two years prior to the case incident, and purchasing an animal at a cattle market all significantly increased the odds of a recent bTB incident (Table 3a). Reporting Johne's disease in the previous year and the presence of maize on or near the farm were not significantly associated with the odds of a bTB incident, but their inclusion improved model fit. Herd size was the dominant risk factor: for every 10 additional animals the odds of a farms being a case increased by $7 \%$. 


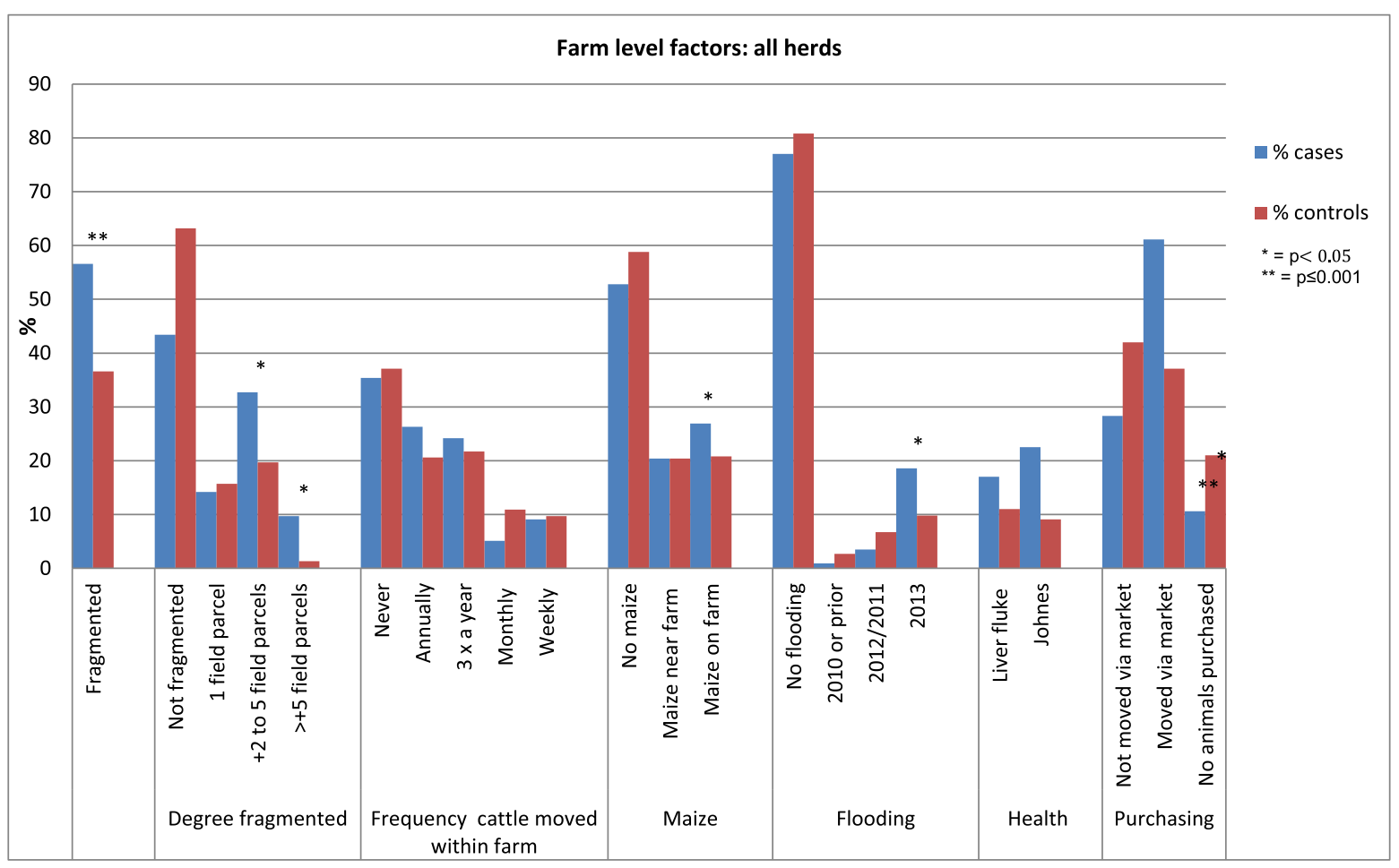

Fig. 3. Descriptive statistics for farm characteristics. P values obtained from univariate conditional logistic regressions.

For beef herds, the size of the herd, using a field parcel more than $3.2 \mathrm{~km}$ away from the main farm, and purchasing cattle from a market all increased the probability of a recent bTB incident (Table $3 \mathrm{~b}$ ). After adjusting for herd size, there was no significant effect of fragmentation as a binary variable. However, farms where the furthest fragment was $3.2 \mathrm{~km}$ (the median) or more in distance were over three times as likely to be case herds. The disclosure of an IR in the two years prior to the incident was not significant but its inclusion improved model fit so was retained. Although growing maize on the farm itself was not significantly associated with having a bTB incident, farms on which maize grew on a neighbouring field were less likely to have a bTB incident. This variable was confounded by herd size.

In dairy herds, the probability of a recent bTB incident was increased in a herd where Johne's disease had been detected, where an IR had been disclosed in the two years before an incident, and as herd size increased (Table $3 c$ ).

Stocking density was negatively associated with being a case (OR 0.71, 95\%CI: 0.51-0.99, $\mathrm{p}=0.04$ ). However, post estimation revealed the model parameters for stocking density to be negatively correlated with Johne's disease, herd size \& a history of IRs. When stocking density was removed from the model the relationship between a bTB incident and all the other remaining variables was similar but the standard errors and confidence intervals were narrower. The model with the highest pseudo $\mathrm{R}^{2}$, lowest AIC and with the lowest standard errors for the estimates used untransformed independent variables.

\subsection{Farmer perception \& biosecurity practices}

None of the cattle biosecurity measures were significantly different across the cases and controls in the univariable analyses, and all had a $P>0.2$ so were not eligible for inclusion in the statistical modelling, although they were included because of their importance. All four of the badger biosecurity measures were more common in herds with a case (Supplementary material Table 5).
The associations were similar in dairy herds. Of dairy herds with a recent history of a case, $76.7 \%$ implemented at least one form of badger biosecurity measure in the previous 12 months compared with $39.3 \%$ of dairy control herds. $71.4 \%$ of beef herds implemented badger biosecurity compared with $45.0 \%$ of control beef herds, with the most popular being raising feed and water troughs.

There were a number of univariable differences between case and control herds in relation to farmer perceptions and attitudes (Supplementary material Table 6). Case farmers felt bTB was spreading faster in their area than controls, more of them believed bTB was endemic in the badger population and while they scored the threat from badgers significantly higher than controls, they felt significantly less under threat from cattle than control farmers $(p<0.05)$. More case farmers disagreed that advice from their private veterinarian or other farmers could reduce their risk of experiencing an incident. There were no major differences in the responses to these questions by herd type.

In the regression modelling, raising feed or water troughs and fencing off badger setts (in the previous year) was significantly positively associated with a recent bTB incident with case herds 4.7 and 4.3 times as likely to do this, respectively (Table 4a). Four of the principal component variables were eligible for inclusion in the model (supplementary material Fig. S1), but the only significant farmer perception variable was the influence of others component, which was negatively associated with the presence of a case. Case farms were less likely to think that other people or institutions (vets/government/APHA) could help. These variables significantly improved the pseudo $\mathrm{R}^{2}$ of the models from 0.42 to 0.58 (Tables 3 and 4). The addition of badger biosecurity measures to the farm characteristics model resulted in a decrease in the Wald test for purchasing cattle via markets, although there was no evidence of substantial multi-collinearity in the correlations of the parameter estimates. A composite variable identifying herds that had implemented at least one cattle biosecurity measure was included in the model but was not significant. 
Table 3

Farm characteristics and management factors identified by conditional logistic multivariable regression associated with the odds of being a case.

\begin{tabular}{|c|c|c|c|c|c|c|c|}
\hline \multirow{2}{*}{$\begin{array}{l}\text { Factor } \\
\text { a) All herds }\end{array}$} & \multirow[t]{2}{*}{ Level } & \multirow[t]{2}{*}{$\begin{array}{l}\text { Odds } \\
\text { Ratio }\end{array}$} & \multicolumn{2}{|c|}{$\begin{array}{l}\text { 95\% Confidence } \\
\text { Interval }\end{array}$} & \multirow[t]{2}{*}{$\mathrm{P}$} & \multirow[t]{2}{*}{ Pseudo R2 } & \multirow[t]{2}{*}{ AIC } \\
\hline & & & & & & & \\
\hline Herd size & per 10 animals & 1.07 & 1.04 & 1.10 & $<0.001$ & 0.43 & 137.4 \\
\hline Inconclusive Reactors (IR) & per IR & 1.95 & 1.29 & 2.97 & 0.002 & & \\
\hline $\begin{array}{l}\text { Number of contiguous } \\
\text { breakdowns }(\log +1)\end{array}$ & & 2.30 & 1.11 & 4.74 & 0.024 & & \\
\hline \multirow{3}{*}{ Purchasing via Markets } & Not purchased through a market & Ref. & & & & & \\
\hline & Purchased through a market & 2.60 & 1.20 & 5.63 & 0.015 & & \\
\hline & No purchasing & 1.07 & 0.39 & 2.99 & 0.998 & & \\
\hline Maize on Farm & Yes & 0.88 & 0.35 & 2.26 & 0.795 & & \\
\hline Johnes' Disease & Recorded $^{1}$ & 1.77 & 0.63 & 4.95 & 0.277 & & \\
\hline \multicolumn{8}{|l|}{ (b) Beef animals only } \\
\hline Herd size & per 10 animals & 1.07 & 1.01 & 1.14 & 0.018 & 0.41 & 92.2 \\
\hline \multirow[t]{3}{*}{ Fragmentation } & No fragmentation & Ref & & & & & \\
\hline & $<3.2 \mathrm{~km}$ & 0.66 & 0.18 & 2.36 & 0.518 & & \\
\hline & $>3.2 \mathrm{~km}$ & 3.28 & 1.20 & 9.02 & 0.021 & & \\
\hline Inconclusive Reactors (IR) & per IR & 2.29 & 0.85 & 6.16 & 0.100 & & \\
\hline \multirow[t]{3}{*}{ Purchasing via Markets } & Not purchased via market & Ref & & & & & \\
\hline & Purchased via market & 3.16 & 1.15 & 8.64 & 0.025 & & \\
\hline & No purchasing & 1.57 & 0.44 & 5.65 & 0.490 & & \\
\hline \multirow[t]{3}{*}{ Maize } & No maize & Ref & & & & & \\
\hline & Maize near farm & 0.25 & 0.07 & 0.94 & 0.041 & & \\
\hline & Maize on farm & 0.34 & 0.07 & 1.66 & 0.184 & & \\
\hline Liverfluke & Recorded $^{1}$ & 6.06 & 0.61 & 60.37 & 0.124 & & \\
\hline $\begin{array}{l}\text { Proportion of herd sent to slaughter } \\
\text { (A) Dairy animals only }\end{array}$ & & 3.86 & 0.26 & 57.29 & 0.327 & & \\
\hline Herd size & per 10 animals & 1.10 & 1.04 & 1.17 & 0.001 & 0.62 & 39.78 \\
\hline Inconclusive Reactors (IR) & per IR & 2.11 & 1.31 & 3.41 & 0.002 & & \\
\hline Johnes Disease & Recorded $^{1}$ & 4.67 & 1.11 & 19.63 & 0.035 & & \\
\hline
\end{tabular}

1 Recorded in the year prior to the survey.

The model including farmer perception and biosecurity variables was almost identical to the main model when applied to beef herds alone (Table $4 \mathrm{~b}$ ). In dairy herds, none of the individual badger biosecurity activities significantly altered the odds of a case, although in the dairy model, case herds were less likely to be influenced by others (Table 4c).

\section{Discussion}

Even in a rapidly spreading epidemic there still will be farms that contract disease first and farms that remain disease-free. Identifying the factors that predispose a farm to a bTB incident in emerging endemic areas is key to determining how best to stall disease spread. Previous work mapping endemic spread indicated that highly variable rates of spread could occur in relatively close proximity (Brunton et al., 2015) and it was clear from the source data that incidents were over-represented in dairy herds, so herds were matched on production type, location and a rate of spread category. This eliminated these confounders and facilitated the identification of other important factors that were not dependent on location or production. While other studies have investigated risk factors for bTB in England and Wales, these have been focussed on counties with a high bTB incidence, prior to the 2001 FMD outbreak (Johnston et al., 2005; Mathews et al., 2006; Reilly and Courtenay, 2007) or in relation to the Randomised Badger Culling Trial (Johnston et al., 2005; Ramírez-Villaescusa et al., 2010). Our study is the first specifically conducted on areas that have recently changed from low bTB prevalence to endemicity and the first to consider the incorporation of farmer opinion and attitudes in a risk factor analysis for bTB in GB.

We used a retrospective, matched case-control study design to assess the importance of different risk factors on the odds of a bTB incident. Previous risk factor studies have used retrospective unmatched case control studies (Marangon et al., 1998; Denny and Wilesmith, 1999; Mathews et al., 2006; Reilly and Courtenay, 2007;
Vial et al., 2011), have matched on location (Johnston et al., 2005) or on multiple herd and location characteristics (Johnston et al., 2011). The over-representation of dairy herds in our potential case population is consistent with other studies that have shown dairy cattle to have a higher risk of bTB than beef (Olea-Popelka et al., 2004; Porphyre et al., 2008; Ramírez-Villaescusa et al., 2010; Vial et al., 2011) as a result of their longer lifespan (Griffin et al., 1996; BrooksPollock et al., 2013) and intensive method of production (Griffin et al., 1993; Goodchild and Clifton-Hadley, 2001; Brooks-Pollock et al., 2013).

The first of our two model sets includes farm characteristics that are largely fixed in time and these factors could be considered predictors of a bTB incident, rather than a consequence of disease status. The second set of models includes the main farm characteristics model, but with the addition of the more subjective farmer perception and self-reported biosecurity behaviour. These are subject to social desirability bias and could also have been shaped by the experience of a bTB incident, rather than operating as a predictor.

Caution should be exercised in the causal interpretation of the factors identified. Although model construction was sensitive to multi-collinearity, a certain amount of co-dependence may be inherent between some of the explanatory variables. The large number of explanatory variables extracted from different data sources increases the probability of the identification of spurious relationships and it is possible that there are other confounding factors of importance not tested or identified here. Stratifying the analyses by herd type does result in a loss of power and consequently non-significant effects should be interpreted carefully, However, in all analyses the sample size was sufficient to detect the relatively high odds ratios estimated and the models are relatively consistent with each other.

The factors that may predispose or protect herds against bTB are less well known in emerging endemic areas and may differ from those in traditionally high risk areas. Johnston et al. (2011) 
Table 4

Farm characteristics, biosecurity and farmer perceptions and attitudes. identified by conditional logistic multivariable regression associated with the odds of being a case.

\begin{tabular}{|c|c|c|c|c|c|c|c|}
\hline \multirow{2}{*}{$\begin{array}{l}\text { Factor } \\
\text { (A) All herds* }\end{array}$} & \multirow[t]{2}{*}{ Level } & \multirow[t]{2}{*}{$\begin{array}{l}\text { Odds } \\
\text { Ratio }\end{array}$} & \multicolumn{2}{|c|}{$\begin{array}{l}\text { 95\% Confidence } \\
\text { Interval }\end{array}$} & \multirow[t]{2}{*}{$\mathrm{P}$} & \multirow[t]{2}{*}{ Pseudo R2 } & \multirow[t]{2}{*}{ AIC } \\
\hline & & & & & & & \\
\hline Herd size & per 10 animals & 1.09 & 1.04 & 1.14 & $<0.001$ & 0.579 & 100.58 \\
\hline Inconclusive Reactors (IR) & per IR & 2.27 & 1.30 & 4.01 & 0.004 & & \\
\hline The number of contiguous breakdowns (all) & $\log 10+1$ & 2.15 & 0.79 & 5.84 & 0.135 & & \\
\hline \multirow[t]{3}{*}{ Purchasing via Markets } & Not purchased through a market & Ref. & & & & & \\
\hline & Purchased through a market & 1.85 & 0.69 & 5.00 & 0.222 & & \\
\hline & No purchasing & 0.86 & 0.22 & 3.25 & 0.819 & & \\
\hline Maize on Farm & Yes & 0.79 & 0.20 & 3.04 & 0.729 & & \\
\hline Johnes' Disease & Recorded $^{1}$ & 1.69 & 0.48 & 5.93 & 0.411 & & \\
\hline Raise feed \& water troughs & Yes & 4.79 & 1.84 & 12.50 & 0.001 & & \\
\hline Fence off badger setts & Yes & 4.34 & 1.10 & 17.11 & 0.036 & & \\
\hline Influence of others & & 0.53 & 0.32 & 0.89 & 0.016 & & \\
\hline \multicolumn{8}{|l|}{ (B) Beef herds only } \\
\hline Herd size & per 10 animals & 1.10 & 1.01 & 1.20 & 0.031 & 0.561 & 70.48 \\
\hline \multirow[t]{3}{*}{ Fragmentation } & No fragmentation & Ref & & & & & \\
\hline & $<3.2 \mathrm{~km}$ & 0.77 & 0.15 & 4.01 & 0.757 & & \\
\hline & $>3.2 \mathrm{~km}$ & 3.66 & 0.86 & 15.51 & 0.079 & & \\
\hline Inconclusive Reactors (IR) & per IR & 5.46 & 0.85 & 35.13 & 0.074 & & \\
\hline Purchasing via & Not purchased via market & Ref & & & & & \\
\hline \multirow[t]{2}{*}{ Markets } & Purchased via market & 1.79 & 0.48 & 6.59 & 0.383 & & \\
\hline & No purchasing & 1.30 & 0.19 & 8.78 & 0.788 & & \\
\hline \multirow[t]{3}{*}{ Maize } & No maize & Ref. & & & & & \\
\hline & Maize near farm & 0.36 & 0.05 & 2.63 & 0.316 & & \\
\hline & Maize on farm & 0.23 & 0.02 & 2.20 & 0.201 & & \\
\hline Liverfluke & Recorded $^{1}$ & 11.02 & 0.48 & 254.15 & 0.134 & & \\
\hline Proportion of herd sent to slaughter & & 7.08 & 0.15 & 328.73 & 0.318 & & \\
\hline Fence off badger setts & Yes & 10.75 & 0.94 & 122.49 & 0.056 & & \\
\hline Raise feed \& water troughs & Yes & 4.58 & 1.22 & 17.20 & 0.024 & & \\
\hline Influence of others & & 0.49 & 0.25 & 0.98 & 0.042 & & \\
\hline \multicolumn{8}{|l|}{ (C) Dairy herds only } \\
\hline Herd size & per 10 animals & 1.13 & 1.05 & 1.21 & 0.002 & 0.69 & 34.53 \\
\hline Inconclusive Reactors (IR) & per IR & 1.88 & 1.09 & 3.23 & 0.023 & & \\
\hline Johnes Disease & Recorded & 3.95 & 0.80 & 19.61 & 0.093 & & \\
\hline Influence of others & & 0.31 & 0.10 & 0.90 & 0.032 & & \\
\hline
\end{tabular}

described different herd-level risk factors operating in three areas of relatively variable incidence, but all but one (Staffordshire) of these areas would have been considered long-time endemic using our criteria. The risk factors identified here could be categorised into two main elements: factors that affect contact with potentially infectious cattle or wildlife (herd size, fragmentation, purchasing via markets, the number of contiguous breakdowns, maize near the farm), and factors which suggest potential inhibition or poor accuracy of bTB diagnosis (Aranaz et al., 2006) (identification of IRs, detection of Johne's disease).

Herd size has been identified as the single most common risk factor for a bTB incident in GB (Carrique-Mas et al., 2008; BrooksPollock and Keeling, 2009), Ireland (Griffin et al., 1996) and New Zealand (Porphyre et al., 2008). Herd size may be associated with other factors, such as purchasing activity, farm size, number of premises and neighbouring herds; each of which may be independently associated with the risk of a bTB incident. Farm size (acreage) has been associated with a higher probability of a bTB incident (Vial et al., 2011; Mill et al., 2012) and may represent increased risk of infection from contiguous premises. However in the current study, neither farm size nor the number of contiguous premises that had a bTB incident were significant predictors, after controlling for herd size, although this could have been confounded by the matching on location and rate of spread.

The importance of contact between adjacent herds, whether it be lengths of common boundary, fragmentation of holdings, or observed direct contacts with cattle from contiguous farms is associated with bTB status (Griffin et al., 1996; Denny and Wilesmith, 1999; Mathews et al., 2006; Johnston et al., 2011). In addition to the number of contiguous breakdowns surrounding a herd, other proxies for increased contact investigated in the current study were farm fragmentation, nose to nose contact as reported by the farmer, and local within farm movement. Operating over multiple premises or across separated parcels of land have been previously identified as risk factors for bTB (Johnston et al., 2005; Johnston et al., 2011; Mill et al., 2012) as these can increase the number of potentially infectious contacts, either through neighbouring cattle herds or badger setts. In this study, however, it was the distance of the furthest fragment rather than fragmentation alone that increased the likelihood of a recent bTB incident in beef farms.

In contrast to previous studies (Johnston et al., 2005; Reilly and Courtenay, 2007; Johnston et al., 2011), maintenance of a closed herd i.e. a herd into which no movements were recorded in the two years prior to the case incident, was not a significantly protective risk factor in any model, after controlling for herd size, compared to farms that had purchased animals. However, the odd ratios were lower than for those farms that purchased via markets. It is difficult to distinguish between re-infection from wildlife and local cattle-to-cattle spread but this suggests that in regions of locally spreading endemic bTB, local infection in the environment from cattle or wildlife may play a significant role in transmission. This is supported by the finding that maize growing near, but not on a farm is protective against recent bTB, as badgers are reported to be attracted to maize (Lanszki et al., 1999). However, this was a factor only in the beef model, was heavily confounded by herd size and verged on significance, although it was also retained in the main model as it improved model fit.

Multiple studies have identified purchasing cattle to be a risky strategy (Gilbert et al., 2005; Carrique-Mas et al., 2008; Johnston et al., 2011). Here, only herds with cattle purchased at markets in the two years prior to the case incident were more likely to be a case compared to herds that were purchased elsewhere. Two pre- 
vious studies conducted during the RBCT identified markets as a risk factor (Johnston et al., 2005; Ramírez-Villaescusa et al., 2010) although others have found it protective (Johnston et al., 2011). It is likely that those purchasing at market would have very little information on the bTB history of the source herd, rather than those buying from a known and trusted supplier. In addition, the mingling of animals at market presents opportunities, albeit shortlived, for disease spread. Although previous work has identified the bTB history of the source herd as a risk for the purchasing herd (Carrique-Mas et al., 2008; Wolfe et al., 2009; Johnston et al., 2011) the proportion of bought-on animals from a herd that had a history of a bTB incident did not significantly alter the odds of a recent bTB incident. It is also possible that the reported presence of Johne's disease is acting as a proxy for poor cattle biosecurity and that farmers reporting Johne's Disease in the herd may have risky purchasing practices.

Two factors that suggest issues with the performance of the SICCT, the primary method of diagnosis of bTB in England and Wales (de la Rua-Domenech et al., 2006), emerged as risk factors; a history of Johne's Disease and IRs. In dairy herds, even controlling for herd size, dairy farms that reported Johne's disease in the previous 12 months were almost five times as likely to have had recent bTB. Whether this is a cause or consequence of the bTB incident remains unclear, and the cross reactivity between some proteins shared between $M$. bovis and Mycobacterium avium paratuberculosis (MAP), the causative agent of Johne's disease (McDonald et al., 1999; Marassi et al., 2010) needs to be considered. The presence of $M$. bovis was confirmed in all the case incidents included in this study, but false positive results for MAP have been recorded in cattle herds infected with $M$. bovis (Lilenbaum et al., 2009). Infection with MAP has been known to obscure the detection of $M$. bovis in concurrent infections (Aranaz et al., 2006). Herds in which IRs had been previously identified are clearly high risk, suggesting that infection may have been present some time before detection. In beef herds, this variable was not statistically significant $(p=0.1)$ but it was retained as it improved model fit. It is possible that the higher turnover in beef herds would mean that an animal that tested inconclusively to the SICCT would be less likely to still be in the herd two years later. The study largely pre-dates more stringent regulations to the removal of inconclusive reactors in Britain (Defra, 2014). In Ireland, animals that react inconclusively to the SICCT were significantly more likely to have evidence of bTB infection at immediate slaughter (Clegg et al., 2011a) or be diagnosed with bTB up to four years later (Clegg et al., 2011b).

Participatory approaches to epidemiology have highlighted the importance of working with farmers to characterise their understanding of disease risks and include such information in risk factor models (Leach and Scoones, 2013). This participatory approach has mainly been used in developing countries but as Catley, Alders et al. (2012) suggest, could also be used in relation to livestock diseases in the developed world. In relation to bTB in the UK, while previous work has examined farmer behavioural change in relation to new bTB policies (Christley et al., 2011), this is the first attempt to seek to produce and analyse risk factors through participatory engagement with farmers and demonstrates the benefits of collaborative multidisciplinary working, in bringing together the perspectives and experience of different disciplines to explore disease risk.

Traditional epidemiological analysis has been combined with social research in order to identify a key set of risk factors and their potential co-dependencies and explanatory powers. As suggested by participatory epidemiology, the use of qualitative work allowed us to enrich the suite of variables that were to be investigated while modelling approaches allowed us to refine the analysis and pinpoint key explanatory variables and factors. This approach has been methodologically challenging but the results should be of interest to policy makers. Longitudinal and/or qualitative research is required to disentangle pre-existing opinions that may have altered farmers' risk of bTB from how the experience of a bTB incident has shaped their perceptions. For example, it is likely that the case farmers report higher levels of badger biosecurity because of the repercussions resulting from their incident and in response to the advice they received. However, it is also possible that some of these farmers had the same level of biosecurity prior to their incident and were responding to a perceived increase in their risk. We also know that response to any intervention varies according to a range of factors, not just disease incidence. For example, Enticott et al. (2014) found that disease incidence was unconnected to vaccine confidence but trust in government and vaccine confidence were related.

The fact that there are differences in how farmers with recent bTB and those with no direct experience of bTB feel and behave is information that could help inform disease control policy. Recent social research has shown how understanding farmers' behaviours and their perceptions of bTB is crucial in developing better bTB policy (Enticott, 2008; Enticott et al., 2012a,b; Warren et al., 2013), although their conclusions are derived from farmers in broadly defined high-risk bTB counties rather than epidemiologically defined newly endemic areas as in the current study. While, in general, higher proportions of cases than controls implemented badger biosecurity, there was no difference in the proportion that implemented even one approach to cattle purchasing biosecurity. This was consistent with their perceptions of endemicity, with case farmers disagreeing that cattle were a threat and more likely to believe that badgers were a threat. Previous investigation has reported that a majority of farmers were not convinced that moving cattle will spread bTB, a view held more strongly in high incidence areas (Christley et al., 2011).

Overall, and by herd type, farmers that have had a recent bTB incident were less likely to be influenced by others. This consolidated variable represented farmers' belief in the value of following advice in the prevention of bTB, from other farmers, private veterinary surgeons or government. Given that approximately half of farms with OTFW incidents in 2012 had a previous bTB incident in the 3 years prior (Broughan et al., 2015), this has implications for directing policy and disease prevention to farmers that have recently had a bTB incident. Previous research has indicated a lack of trust in government (Defra), particularly in counties with a longstanding high bTB incidence (Enticott, 2008; Christley et al., 2011). In the focus groups conducted before deployment of the questionnaire, farmers consistently identified "institutional failure" as a risk factor, but we were unable to quantify and describe this adequately.

Overall, the key finding from these analyses is that risk factors vary according to production practice. But also, and given these key variations, avoiding purchasing through markets and, for beef herds, operating field parcels close to the main enterprise is likely to reduce the risk of bTB in newly endemic areas. Farmers appear reluctant to trust advice on preventive cattle measures, and are more likely to implement badger biosecurity after they experience a bTB incident. This suggests that efforts to advise farmers on bTB preventive measures need to focus on farmers without bTB or that alternative methods of engaging with farmers who have recently had an incident may need to be developed (Enticott et al., 2012a,b). However, the lack of trust farmers place in such advice may require alternative routes to those currently being used.

\section{Acknowledgements}

This research was funded by Defra (project code SE3045). We would like to thank the farmers and vets that participated in the research; Alison Prosser (APHA) for data support; Rosie Sallis and Jemma Aston (APHA) for project management, and Sara Downs, 
Amie Adkin and Colin Birch (APHA) for additional support. Thanks to the SE3045 project board for their contribution to the project. Thanks to Nick Lewis, Will Barber, Erin Shrimpton, Phil Wilson, Jacquetta Whatt-Watts, Alice Hamilton-Webb and Bethany Ledingham who conducted telephone interviews and Rob Berry for database assistance. Many thanks to Professor Glyn Hewinson, APHA and Professor Dirk Pfeiffer, RVC for helpful comments on the manuscript.

\section{Appendix A. Supplementary data}

Supplementary data associated with this article can be found, in the online version, at http://dx.doi.org/10.1016/j.prevetmed.2016. 05.007 .

\section{References}

Abernethy, D.A., Upton, P., Higgins, I.M., McGrath, G., Goodchild, A.V., Rolfe, S.J., Broughan, J.M., Downs, S.H., Clifton-Hadley, R., Menzies, F.D., de la Rua-Domenech, R., Blissitt, M.J., Duignan, A., More, S.J., 2013. Bovine tuberculosis trends in the UK and the Republic of Ireland, 1995-2010. Vet. Rec 172 (12), 312.

Aranaz, A., De Juan, L., Bezos, J., Alvarez, J., Romero, B., Lozano, F., Paramio, J.L., Lopez-Sanchez, J., Mateos, A., Dominguez, L., 2006. Assessment of diagnostic tools for eradication of bovine tuberculosis in cattle co-infected with Mycobacterium bovis and M. avium subsp. paratuberculosis. Vet. Res. 37 (4), 593-606.

Brooks-Pollock, E., Keeling, M., 2009. Herd size and bovine tuberculosis persistence in cattle farms in Great Britain. Prev. Vet. Med. 92 (4), 360-365.

Brooks-Pollock, E., Conlan, A.J., Mitchell, A.P., Blackwell, R., McKinley, T.J., Wood, J.L., 2013. Age-dependent patterns of bovine tuberculosis in cattle. Vet. Res. 44, 97.

Broughan, J.M., Harris, K.A., Brouwer, A., Downs, S.H., Goodchild, A.V., Upton, P.A., Smith, N.H., 2015. Bovine TB infection status in cattle in Great Britain in 2013. Vet. Rec. 176 (13), 326-330.

Brunton, L.A., Nicholson, R., Ashton, A, Alexander, N., Wint, W., Enticott, G., Ward, K., Broughan, J.M., Goodchild, A.V., 2015. A novel approach to mapping and calculating the rate of spread of endemic bovine tuberculosis in England and Wales. Spatial Spatiotemporal Epidemiol. 13, 41-50.

Carrique-Mas, J.J., Medley, G.F., Green, L.E., 2008. Risks for bovine tuberculosis in British cattle farms restocked after the foot and mouth disease epidemic of 2001. Prev. Vet. Med. 84 (1/2), 85-93.

Catley, A., Alders, R.G., Wood, J.L.N., 2012. Participatory epidemiology: approaches, methods, experiences. Vet. J. 191 (2), 151-160.

Christley, R.M., Robinson, S.E., Moore, B., Setzkorn, C., Donald, I., 2011. Responses of farmers to introduction in England and Wales of pre-movement testing for bovine tuberculosis. Prev. Vet. Med. 100 (2), 126-133.

Clegg, T.A., Good, M., Duignan, A., Doyle, R., More, S.J., 2011a. Shorter-term risk of Mycobacterium bovis in Irish cattle following an inconclusive diagnosis to the single intradermal comparative tuberculin test. Prev. Vet. Med. 102 (4), $255-264$

Clegg, T.A., Good, M., Duignan, A., Doyle, R., Blake, M., More, S.J., 2011b. Longer-term risk of Mycobacterium bovis in Irish cattle following an inconclusive diagnosis to the single intradermal comparative tuberculin test. Prev. Vet. Med. 100 (3-4), 147-154.

de la Rua-Domenech, R., Goodchild, A.T., Vordermeier, H.M., Hewinson, R.G., Christiansen, K.H., Clifton-Hadley, R.S., 2006. Ante mortem diagnosis of tuberculosis in cattle: a review of the tuberculin tests, [gamma]-interferon assay and other ancillary diagnostic techniques. Res. Vet. Sci. 81 (2), 190-210.

Defra (2014) The Strategy for Achieving Officially Bovine Tuberculosis Free Status for England. https://www.gov.uk/government/uploads/system/uploads attachment_data/file/300447/pb14088-bovine-tb-strategy-140328.pdf (accessed 24.03.16.)

Denny, G.O., Wilesmith, J.W., 1999. Bovine tuberculosis in Northern Ireland: a case-control study of herd risk factors. Vet. Rec. 144 (12), 305-310.

Enticott, G., Franklin, A., Van Winden, S., 2012a. Biosecurity and food security: spatial strategies for combating bovine tuberculosis in the UK. Geogr. J. 178, 327-337

Enticott, G., Maye, D., Ilbery, B., Fisher, R., Kirwan, J., 2012b. Farmers' confidence in vaccinating badgers against bovine tuberculosis. Vet. Rec. 170 (8), 204.

Enticott, G., Maye, D., Fisher, R., Ilbery, B., Kirwan, J., 2014. Badger vaccination: dimensions of trust and confidence in the governance of animal disease. Environ. Plan. A 46, 2881-2897.

Enticott, G., Maye, D., Carmody, P., Naylor, R., Ward, K., Hinchliffe, S., Eglin, R., Ashton, A., Brunton, L., Upton, P., Wint, W., Alexander, N., Goodchild, A.V., Nicholson, R., Broughan, J.M., 2015. Farming on the edge: farmer attitudes to bovine tuberculosis in newly endemic areas. Vet. Rec. 177 (17), 439.

Enticott, G., 2008. The ecological paradox: social and natural consequences of the geographies of animal health promotion. Trans. Inst. Br. Geogr. 33, 433-446.

Garro, C., Abdala, A., Garbaccio, S., Spath, E., Leon, E., Paolicchi, F., 2010. Risk factors for bovine tuberculosis in dairy herds in Cordoba and Santa Fe provinces
(Factores de riesgo de tuberculosis bovina en rodeos lecheros de las provincias de Cordoba y Santa Fe). Revista Argentina de Producción Anim. 30 (2), 167-178. Gilbert, M., Mitchell, A., Bourn, D., Mawdsley, J., Clifton-Hadley, R., Wint, W., 2005. Cattle movements and bovine tuberculosis in Great Britain. Nature 435 (7041), 491-496.

Goodchild, A.V., Clifton-Hadley, R.S., 2001. Cattle-to-cattle transmission of Mycobacterium bovis. Tuberculosis (Edinb.) 81 (1-2), 23-41.

Griffin, J.M., Hahesy, T., Lynch, K., Salman, M.D., McCarthy, J., Hurley, T., 1993. The association of cattle husbandry practices, environmental factors and farmer characteristics with the occurrence of chronic bovine tuberculosis in dairy herds in the Republic of Ireland. Prev. Vet. Med. 17 (3/4), 145-160.

Griffin, J.M., Martin, S.W., Thorburn, M.A., Eves, J.A., Hammond, R.F., 1996. A case-control study on the association of selected risk factors with the occurrence of bovine tuberculosis in the Republic of Ireland. Prev. Vet. Med. 27 (1/2), 75-87.

Hosmer, D.W., Lemeshow, S., Sturdivant, R.X., 2013. Applied Logistic Regression. Wiley.

Humblet, M.F., Gilbert, M., Govaerts, M., Fauville-Dufaux, M., Walravens, K., Saegerman, C., 2010. New assessment of bovine tuberculosis risk factors in Belgium based on nationwide molecular epidemiology. J. Clin. Microbiol. 48 (8), 2802-2808

Javed, M.T., Irfan, M., Imtiaz, A., Farooqi, F.A., Wasiq, M., Cagiola, M., 2011. Risk factors identified associated with tuberculosis in cattle at 11 livestock experiment stations of Punjab Pakistan. Acta Trop. 117 (2), 109-113.

Johnston, WT. Gettinby, G., Cox, D.R., Donnelly, C.A., Bourne, J., Clifton-Hadley, R, Le Fevre, A.M., McInerney, J.P., Mitchell, A., Morrison, W.I., Woodroffe, R., 2005 Herd-level risk factors associated with tuberculosis breakdowns among cattle herds in England before the 2001 foot-and-mouth disease epidemic. Biol. Lett. $1(1), 53-56$.

Johnston, W.T., Vial, F., Gettinby, G., Bourne, F.J., Clifton-Hadley, R.S., Cox, D.R., Crea, P., Donnelly, C.A., McInerney, J.P., Mitchell, A.P., Morrison, W.I., Woodroffe, R., 2011. Herd-level risk factors of bovine tuberculosis in England and Wales after the 2001 foot-and-mouth disease epidemic. Int. J. Infect. Dis. 15 (12), e833-e840

Kaneene, J.B., Bruning-Fann, C.S., Granger, L.M., Miller, R.A., Porter-Spalding, B.A., 2002. Environmental and farm management factors associated with tuberculosis on cattle farms in northeastern Michigan. J. Am. Vet. Med. Assoc 221 (6), 837-842.

Karolemeas, K., McKinley, T.J., Clifton-Hadley, R.S., Goodchild, A.V., Mitchell, A. Johnston, W.T., Conlan, A.J., Donnelly, C.A., Wood, J.L., 2011. Recurrence of bovine tuberculosis breakdowns in Great Britain: risk factors and prediction. Prev. Vet. Med. 102 (1), 22-29.

Kristensen, E., Jakobsen, E.B., 2011. Challenging the myth of the irrational dairy farmer; understanding decision-making related to herd health. N. Z. Vet. J. 59 (1), 1-7.

Lanszki, J., Kormendi, S., Hancz, C., Zalewski, A., 1999. Feeding habits and trophic niche overlap in a Carnivora community of Hungary. Acta Theriol. (Warsz.) 44, 429-442.

Leach, M., Scoones, I., 2013. The social and political lives of zoonotic disease models: narratives, science and policy. Social Sci. Med. 88 (0), 10-17.

Lilenbaum, W., Marassi, C.D., Varges, R., Medeiros, L., Oelemann, W.M., Fonseca, L.S., 2009. Occurrence of false-positive results in three paratuberculosis-ELISAs performed in a tuberculous herd. Vet. Res. Commun. 33 (7), 693-699.

Marangon, S., Martini, M., Pozza, M.D., Ferreira Neto, J., 1998. A case-control study on bovine tuberculosis in the Veneto Region (Italy). Prev. Vet. Med. 34 (2/3), 87-95.

Marassi, C.D., McNair, J., Pollock, J., Ristow, P., Fonseca, L.S., Oelemann, W.M., Lilenbaum, W., 2010. The use of MPB70 and MPB83 to distinguish between bovine tuberculosis and paratuberculosis. Comp. Immunol. Microbiol. Infect. Dis. 33, 485-489.

Mathews, F., Lovett, L., Rushton, S., Macdonald, D.W., 2006. Bovine tuberculosis in cattle: reduced risk on wildlife-friendly farms. Biol. Lett. 2 (2), 271-274.

McDonald, W.L., Ridge, S.E., Hope, A.F., Condron, R.J., 1999. Evaluation of diagnostic tests for Johne's disease in young cattle. Aust. Vet. J. 77, 113-119.

Mill, A.C., Rushton, S.P., Shirley, M.D.F., Murray, A.W.A., Smith, G.C., Delahay, R.J., McDonald, R.A., 2012. Farm-scale risk factors for bovine tuberculosis incidence in cattle herds during the Randomized Badger Culling Trial. Epidemiol. Infect. 140 (2), 219-230.

Olea-Popelka, F.J., White, P.W., Collins, J.D., O'Keeffe, J., Kelton, D.E., Martin, S.W., 2004. Breakdown severity during a bovine tuberculosis episode as a predicto of future herd breakdowns in Ireland. Prev. Vet. Med. 63 (3-4), 163-172.

Porphyre, T., Stevenson, M.A., McKenzie, J., 2008. Risk factors for bovine tuberculosis in New Zealand cattle farms and their relationship with possum control strategies. Prev. Vet. Med. 86 (1/2), 93-106.

Ramírez-Villaescusa, A.M., Medley, G.F., Mason, S., Green, L.E., 2010. Risk factors for herd breakdown with bovine tuberculosis in 148 cattle herds in the south west of England. Prev. Vet. Med. 95 (3-4), 224-230.

Reilly, L.A., Courtenay, O., 2007. Husbandry practices, badger sett density and habitat composition as risk factors for transient and persistent bovine tuberculosis on UK cattle farms. Prev, Vet. Med. 80 (2/3), 129-142.

Vial, F., Johnston, W.T., Donnelly, C.A., 2011. Local cattle and badger populations affect the risk of confirmed tuberculosis in British cattle herds. PLoS One 6 (3), e18058.

Warren, M., Lobley, M., Winter, M., 2013. Farmer attitudes to vaccination and culling of badgers in controlling bovine tuberculosis. Vet. Rec. 
Wentholt, M.T.A., Cardoen, S., Imberechts, H., Van Huffel, X., Ooms, B.W., Frewer, L.J., 2012. Defining European preparedness and research needs regarding emerging infectious animal diseases: results from a Delphi expert consultation. Prev. Vet. Med. 103 (2-3), 81-92.

White, P.W., Martin, S.W., De Jong, M.C.M., O’Keeffe, J.J., More, S.J., Frankena, K., 2013. The importance of 'neighbourhood' in the persistence of bovine tuberculosis in Irish cattle herds. Prev. Vet. Med. 110 (3-4), 346-355.
Wolfe, D.M., Berke, O., More, S.J., Kelton, D.F., White, P.W., O’Keeffe, J.J., Martin, S.W., 2009. The risk of a positive test for bovine tuberculosis in cattle purchased from herds with and without a recent history of bovine tuberculosis in Ireland. Prev. Vet. Med. 92 (1/2), 99-105. 